\title{
Monogenean infestations and mortality in wild and cultured Red Sea fishes
}

\author{
I. Paperna, ${ }^{1}$, A. Diamant ${ }^{1}$ \& R. M. Overstreet ${ }^{2}$ \\ 1 The H. Steinitz Marine Biology Laboratory of the Hebrew University of Jerusalem; \\ Eilat, Israel \\ ${ }^{2}$ Gulf Coast Research Laboratory; Ocean Springs, Mississippi, USA
}

\begin{abstract}
Hyperinfection by the gill-infesting monogenean Allobivagina sp. (Microcotylea) caused mass mortalities in juveniles of Siganus luridus cultured in seawater earthen ponds and holding tanks in Eilat (Gulf of Aqaba, Red Sea). Other species of Siganus and adults of S. luridus cultured in the same systems acquired a low intensity of infestation. Most hyperinfected fish were emaciated and anaemic with hematocrit values below $10 \%$. Skin and mouth infestations by the monogenean Benedenia monticelli (Capsaloidea) caused mass mortalities in grey mullets (Mugilidae). These mortalities occurred in large individuals in wild populations of Liza carinata from lagoonal habitats in the Gulf of Suez and in most species of grey mullets cultured in Eilat. The intensity of infestation correlated positively with severity of infestation, and the common sites of infestation corresponded with areas of severe pathological alterations. Spontaneous recovery followed the climax of an epizootic, both for infested S. luridus and infested grey mullets. Decline in infestation coincided with remission of the pathological signs.
\end{abstract}

\section{INTRODUCTION}

The potential pathogenicity of capsalid (Benedeniinae) and microcotylid monogeneans to marine fishes has been recognized since species caused mortalities of fishes in public aquaria several decades ago (Nigrelli, 1939, 1943). Mortalities due to these pathogenic monogeneans have increased in number with the increased cultivation of marine fishes. In Japan, epizootics of the capsalid Benedenia seriolae and the microcotylid Axine heterocerca caused mass mortalities of cultured yellowtail (Seriola quinqueradiata) (Hoshina, 1968; Eto et al., 1976). In the United States, the microcotylid Bicotylophora trachinoti and Benedenia spp. caused mortalities of cultured Florida pompano (Trachinotus carolinus) (Lawler, 1977; pers. obs.), whereas elsewhere another capsalid, Entobdella solae, caused severe infestations on brood stock of Dover sole (Solea solea) (Anderson \& Conroy, 1968).

The present communication reports morbidity and mortality associated with infestations of a microcotylid on Siganus luridus (Siganidae) and of a capsalid on grey mullets (Mugilidae). Preliminary accounts of the capsalid Benedenia monticelli and its infestation on grey mullets have appeared in two reviews of mullet diseases (Paperna, 1975; Paperna \& Overstreet, 1981). 


\section{MATERIAL and METHODS}

Study incorporates quantitative data from fish sampled from natural habitats in the Gulfs of Suez and Aqaba, Red Sea and observations made on the course of infestations and consequent mortalities in fish maintained in the culture facilities in the H. Steinitz Marine Biology Laboratory located in the northern end of the Gulf of Aqaba.

Culture facilities comprised shallow ( $1 \mathrm{~m}$ deep) earthern ponds, $250 \mathrm{~m}^{2}$ in area, and holding tanks with volumes ranging from 0.75 to $1.5 \mathrm{~m}^{3}$, all supplied by filtered flowing sea water.

From the cultured stock it was not possible to obtain frequent consecutive samples large enough for quantitative evaluation without considerably depleting the fish stock under observation. Thus, data from cultured fish remain of qualitative nature.

Fish were examined for monogeneans as well as for pathological aberrations. Weight (to the nearest $0.1 \mathrm{~g}$ ), length (either fork length [FL] or total length [TL] in $\mathrm{mm}$ ) and hematocrit (in \%) were measured. For determination of hematocrit values, fish were bled by amputation of their posterior end before the caudal peduncle. Blood was collected into standard heparinized micro hematocrit capillary. The capillaries were centrifuged for $3 \mathrm{~min}$ in Microhematocrit centrifuge (Heraeus-Christ $\mathrm{GmbH}$ ) and the hematocrit level in \% was determined from Heraeus-Christ standard chart.

Condition coefficient of the fish was calculated from the equation:

$\mathrm{K}=$ weight $(\mathrm{g}) \times 10 .{ }^{5} /$ length $(\mathrm{mm})^{3}$. To compare the length - weight relationship in different samples, data were transformed with common logarithms and fitted to the regression equation. Co-variance was employed for comparisons between samples. Student t-test, Spearman's coefficient of rank correlation and linear correlation were employed for analysis of data obtained from the different samples, habitats and size groups of fish, and for host-parasite relationships.

Severity of the pathological alterations for quantitative evaluations was subjectively scaled to a maximum 9 units, following the stages in the pathological process as described below.

\section{MICROCOTYLID EPIZOOTICS IN CULTURED SIGANID FISH}

The microcotylid Allobivagina sp. (a new species being studied by Diamant \& Paperna) occurs on the gills of three common northern Red Sea species of Siganus (S. luridus, $S$. rivulatus, and $S$. argenteus) and also on populations of $S$. luridus and $S$. rivulatus in the eastern Mediterranean Sea which originated from Red Sea stock that had passed through the Suez Canal. In these wild fish populations, infestations rarely exceeded 10 parasites per fish, but several fish from both the Red and Mediterranean Seas had infestations reaching 40 to 200 parasites. Nevertheless, no apparent associated pathological damage was evident.

Examination of $S$. luridus from a mass mortality that occurred in November 1974 in a seawater earthen pond in Eilat revealed high numbers of Allobivagina sp. (Fig. 1). The cultured fish, measuring 60 to $80 \mathrm{~mm}$ TL, originated from a wild stock of juveniles 40 to $45 \mathrm{~mm}$ TL captured in August of the same year at the northern shore of the Gulf of Aqaba. Whereas all dead, moribund, and surviving fish had infestations and appeared emaciated, the intensity of infestation varied from 50 to 1133 worms per fish. The lowest number in moribund fish was 150 worms. Many active fish, however, had well above that 


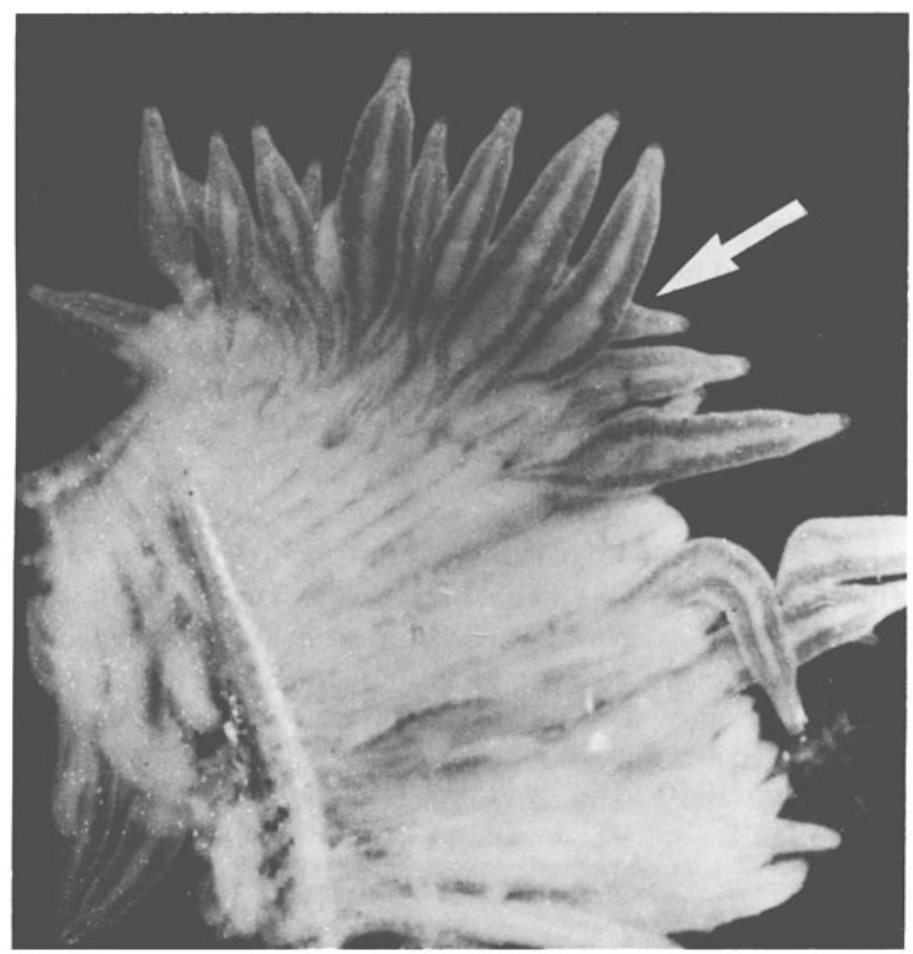

Fig. 1. Infestation of Allobivagina sp. on gills of Siganus luridus $(\times 16)$. Arrow indicates worms

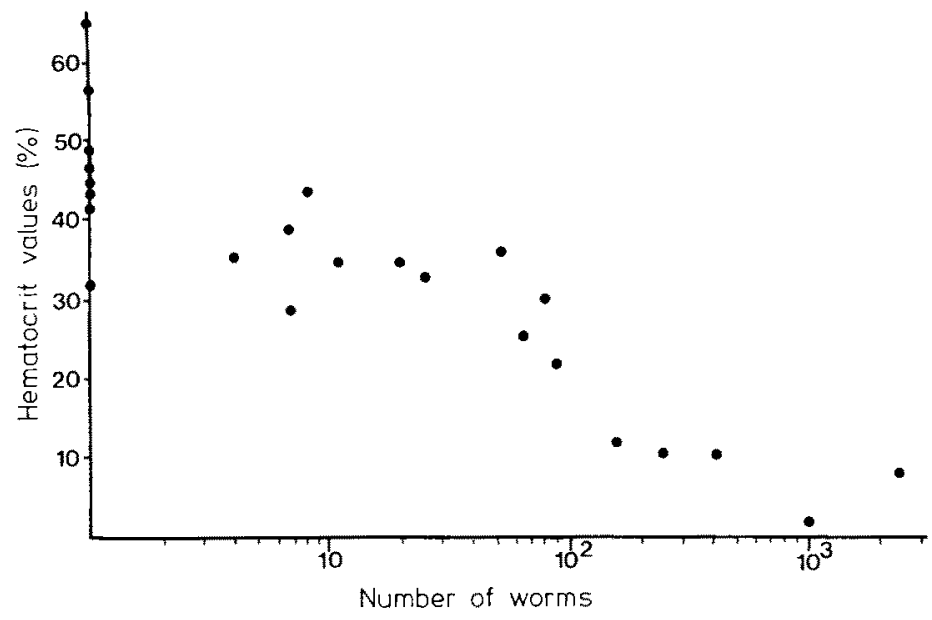

Fig. 2. Relation between hematocrit values (Hct \%) and number of Allobivagina sp. infesting gills of cultured Siganus luridus (70-90 $\mathrm{mm}$ in length) 
minimum. On the other hand, all fish with more than 150 worms exhibited anaemia, with distinctly pale gills and hematocrit levels below $10 \%$; the most anaemic fish had 985 worms and a hematocrit value of $2.5 \%$.

In moderately infested fish ( 70 to 100 worms), the hematocrit ranged between 15 and $30 \%$; hematocrit levels in uninfested fish from the same size group, but maintained in separate holding tanks, ranged from 25 to $50 \%$ (Fig. 2). The correlation between mean intensity of infestation and hematocrit values yielded an exponential regression curve of $\mathrm{Y}=35.561 \mathrm{e}^{-0.003 \mathrm{X}}$ with a correlation coeffecient of 0.91 (with 20 degrees of freedom). Blood smears prepared from anaemic fish revealed predominantly immature erythrocytes (Figs 3-4).

Massive infestations associated with mortalities of $S$. luridus had occurred by December 1974 in another earthen pond apart from that in which the November mortalities had occurred and in two holding tanks, all stocked with fish of similar size from the same locality. The affected fish, including individuals up to $133 \mathrm{~mm} \mathrm{TL}$, had infestations as high as in November and exhibited similar pathological signs of emaciation and anaemia. Massive infestations of Allobivagina sp. were also induced experimentally in two groups of 60 to $90 \mathrm{~mm}$ long fish. In the first instance a group of uninfested fish was placed in a cage which in turn was placed in a pond containing infested fish. In the second instance a few infested fish were introduced into a holding tank containing uninfested fish. The newly infested fish became morbid or died within 3
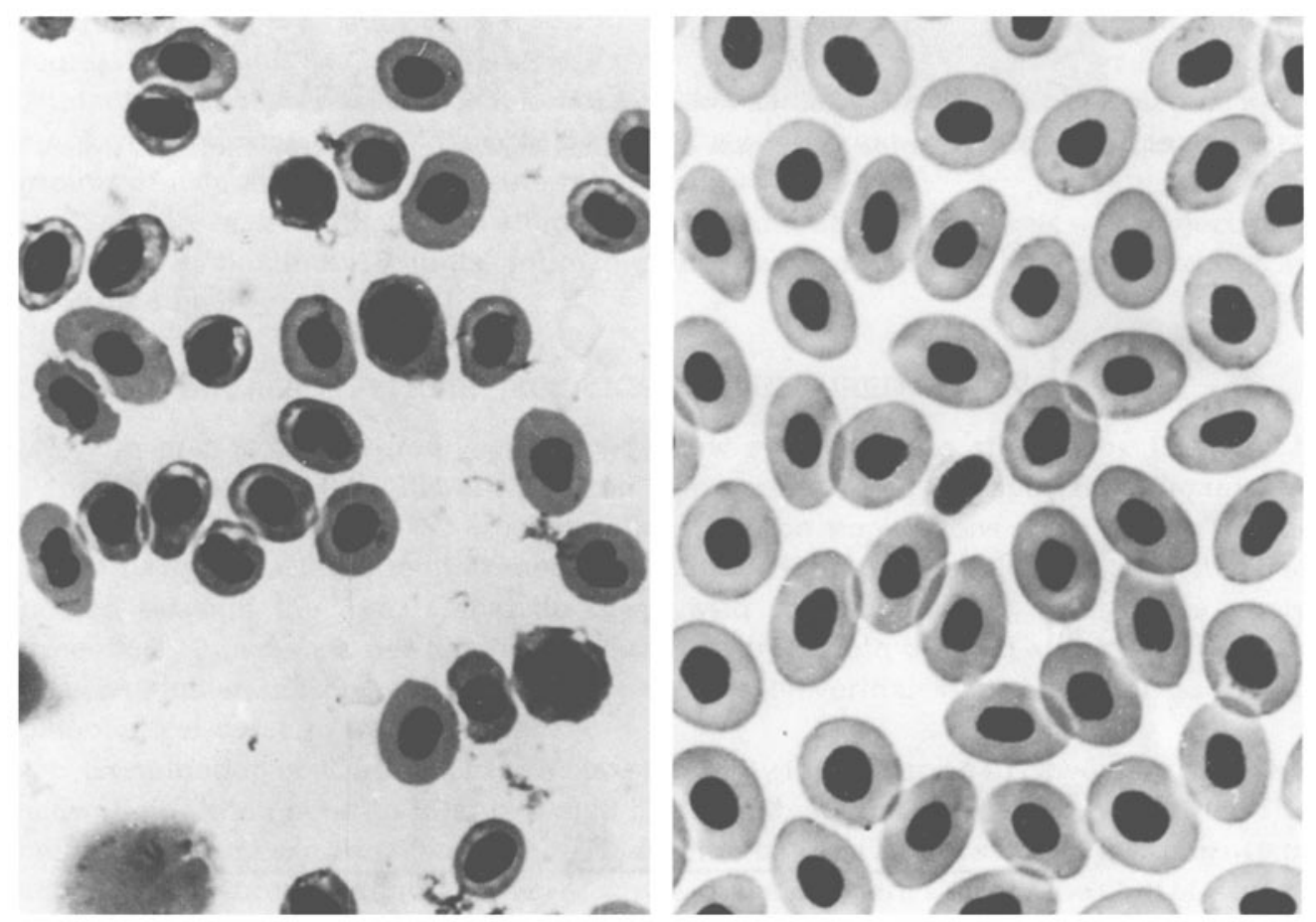

Fig. 3. Blood smear of Siganus luridus heavily infested with Allobivagina sp. and with hematocrit value of $10 \%$ (Methyl alcohol fixation, Giemsa stain)

Fig. 4 (right). Blood smear of Siganus luridus free of infestation (staining method as in Figure 3) 
to 4 weeks. Extensive mortalities occurred sporadically during the period. Whereas high infestations persisted in some fish for a month, intensity of infestation declined in others. Gradually, fish lost all their worms. Fish with infestations of fewer than 50 worms, including uninfested fish, demonstrated apparent recovery, with hematocrit values returning to normal levels of above $30 \%$. Fish treated with a bath of 150 to $200 \mathrm{ppm}$ formalin also lost their infestations and showed restoration of hematocrit levels to normal within one week.

By early March 1975, infestation intensity levels in all groups of $S$. luridus subsided to fewer than 10 worms per fish. Both $S$. rivulatus and $S$. argenteus appeared resistant to mass infestation; individuals of both species reared in ponds and tanks with infested fish never acquired more than 10 worms per fish. Also, specimens of $S$. luridus longer than $200 \mathrm{~mm}$ TL never acquired more than 10 worms. Ambient temperature appeared to have little influence on the epizootics. During periods of infestations, temperatures fluctuated from 13 to $22{ }^{\circ} \mathrm{C}$ in the ponds, but remained relatively constant at 22 to $25^{\circ} \mathrm{C}$ in the flowing seawater tanks.

\section{EPIZOOTICS IN WILD POPULATIONS OF LIZA CARINATA}

Benedenia monticelli (Fig. 5) infested and caused pathological alterations in mullets (e.g. Fig. 6) in El Bilaim Lagoon during mid-April 1974. On a trip to the $5 \mathrm{~km}^{2}$ sandy

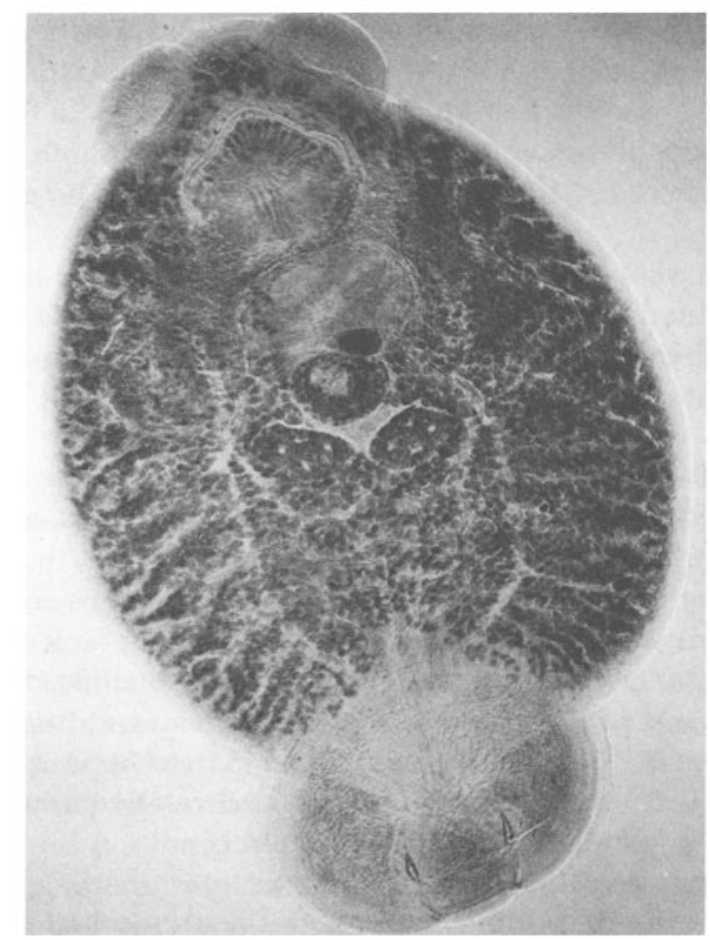

Fig. 5. Benedenia monticelli off Liza carinata from El Bilaim ( $90 \%$ alcohol fixation, alum carmine stain, $\times 24)$ 


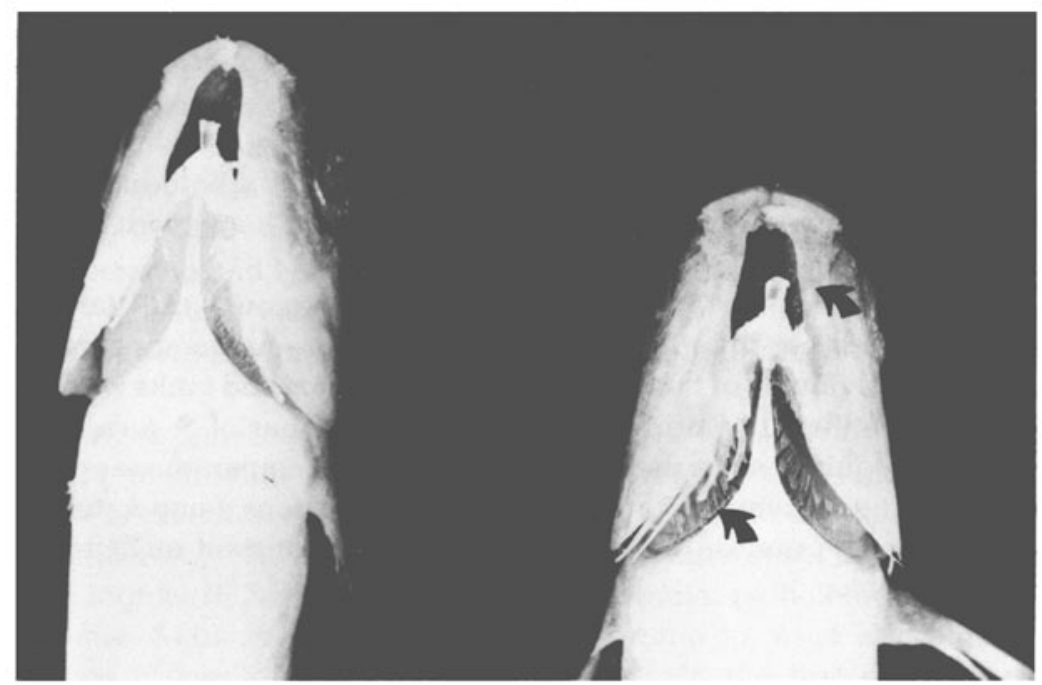

Fig. 6. Moribund Liza ramada involved with Benedenia monticelli epizootic. Note perforation of the intermandibular membranes and erosion of the opercular fold

lagoon situated on the eastern shore of the Gulf of Suez (28 $30^{\prime} \mathrm{E}, 33^{\circ} 17^{\prime} \mathrm{N}$; Fig. 7), we found dead specimens of Liza carinata along the shore. Examination of fish samples from the lagoon revealed several individuals $>100 \mathrm{~mm}$ FL with up to 40 individuals of this relatively large worm. The fish had eroded snouts and lesions in the mouth; some were emaciated. The majority of the sample, including individuals both $\leq 100 \mathrm{~mm}$ and $>100$ $\mathrm{mm} \mathrm{FL}$, however, harbored $<10$ worms (Fig. 8) and exhibited no apparent pathological alterations.

On a subsequent visit to the lagoon in mid-February 1975, numerous dead specimens of $L$. carinata lined the shore, indicating an extensive mass mortality. Sluggishly swimming and moribund individuals occurred in shallow water separate from their schooling counterparts. As in the preceding year, only fish $>100 \mathrm{~mm}$ exhibited a diseased state.

An intensity of 50-300 worms was found in most sampled moribund fish and in most of the sampled actively schooling fish $>100 \mathrm{~mm}$ FL. In fish $\leq 100 \mathrm{~mm}$, found in separate schools, infestations rarely exceeded 20 worms per fish and those fish exhibited no pathological signs (Fig. 8). The above host-parasite relationships are further borne out by analysis of infestations using both Spearman's coefficient of rank correlation and linear correlation. These tests indicated significant relationships when tested at the $5 \%$ level of significance, but most of these and later correlations would have been accepted at much lower levels than $1 \%$. A positive correlation existed between intensity of infestation and length of host and between intensity and relative severity of pathological alterations. A negative correlation existed between condition coefficients $(\mathrm{K})$ and both severity of pathological alterations and intensity of infestation.

The moribund fish, when subjected to " $t$ " test analyses, had a significantly higher intensity of infestation and a significantly lower $\mathrm{K}$ than the sampled actively schooling fish (Table 1). The $\mathrm{K}$ of juveniles, which harbored few worms, was signifcantly higher 


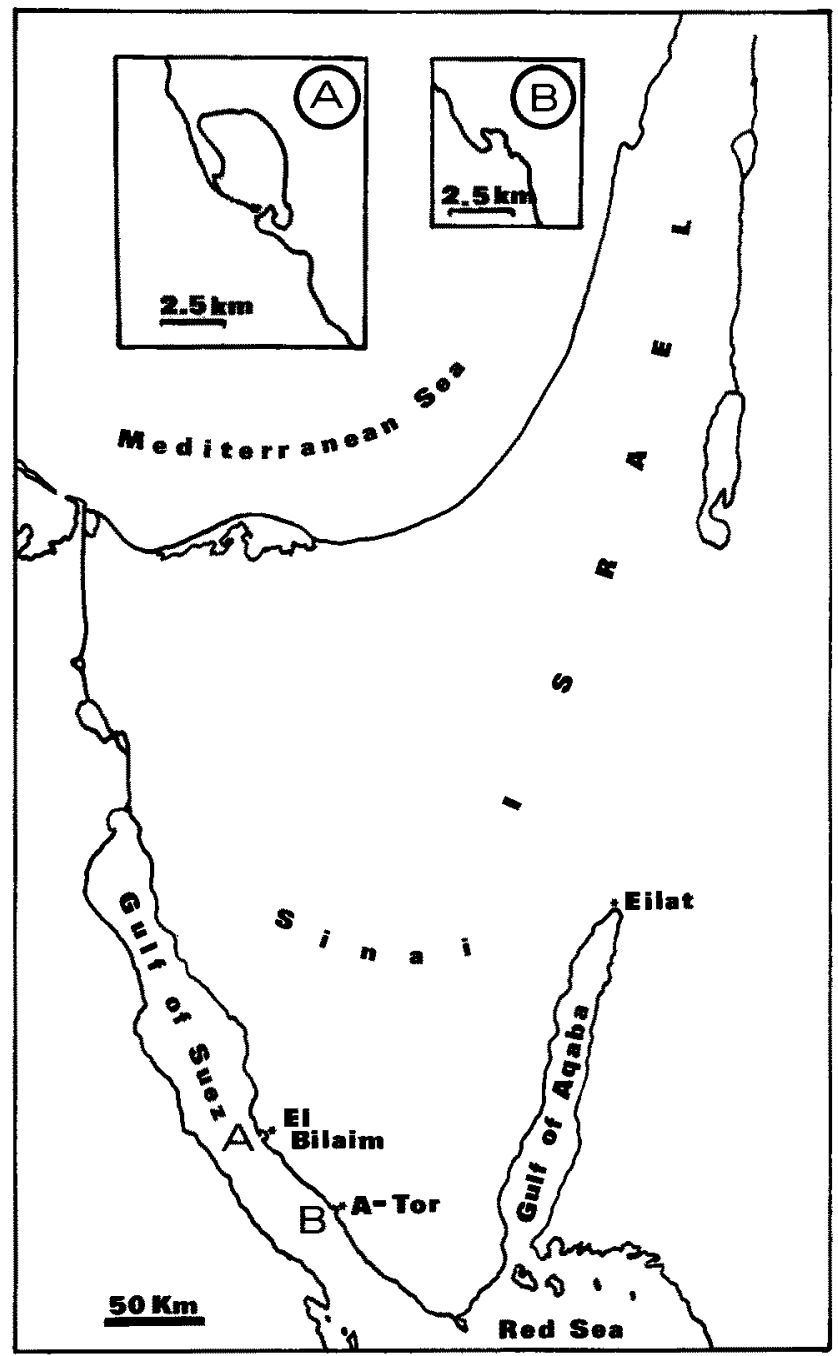

Fig. 7. Map of Sinai peninsula indicating study sites

than for fish $>100 \mathrm{~mm}$. All these larger fish had recently spawned. Other mullets from El Bilaim were examined during the same periods when $L$. carinata had many worms; individuals of Liza subviridus, Valimugil seheli, Crenimugil crenilabis, and Mugil cephalus had an intensity fewer than 10; some had none, and data for those species are not included above.

Subsequent comparative collections from El Bilaim were not feasible, so sampling was shifted to A-Tor Bay and its surroundings, $50 \mathrm{~km}$ further south in the Suez Gulf $\left(28^{\circ} 12^{\prime} \mathrm{E}, 33^{\circ} 38^{\prime} \mathrm{N}\right.$; Fig. 7). Samples of L. carinata $>100 \mathrm{~mm}$ taken during the winter of 1976 revealed a high intensity of infestation; nevertheless, infestations consisted of 


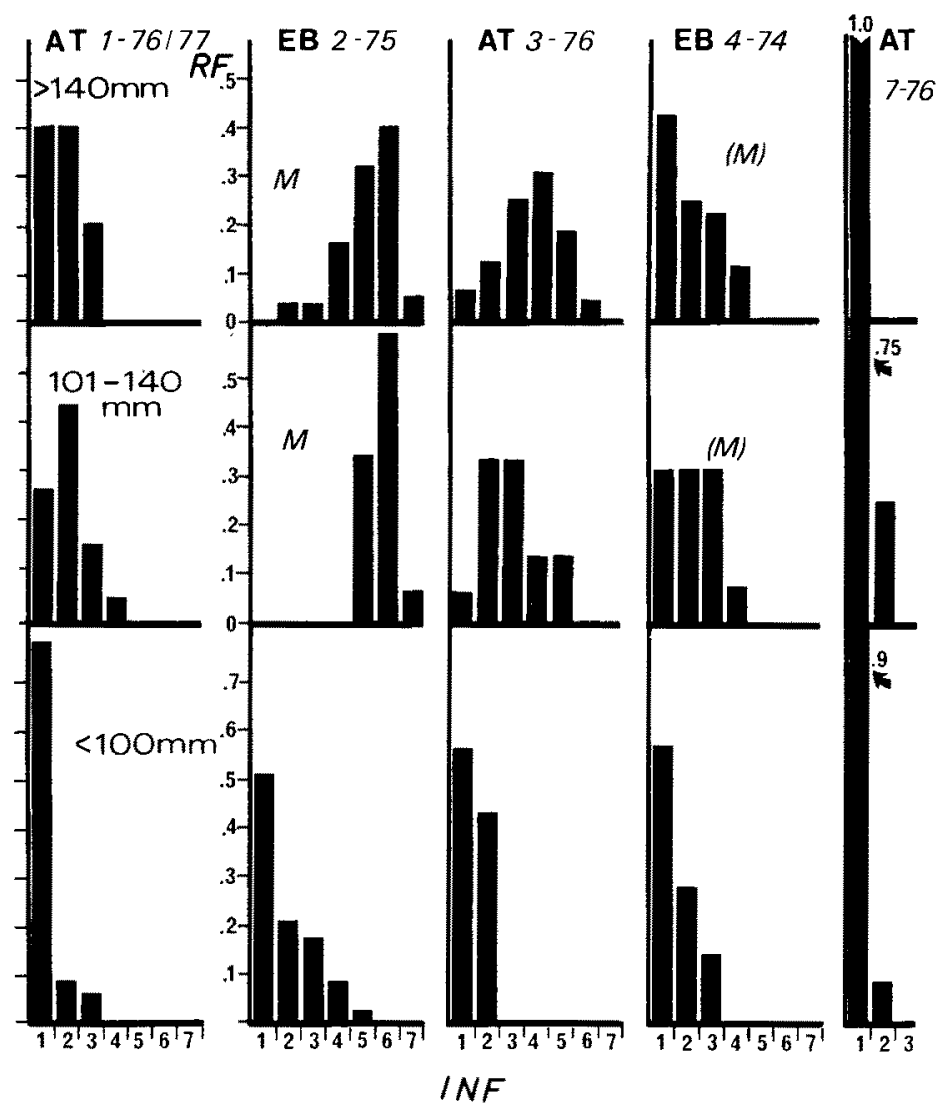

Fig. 8. Relative frequency distribution of Benedenia monticelli on wild Liza carinata from the Gulf of Suez in three size classes ( $F L<100 \mathrm{~mm}, 101-140 \mathrm{~mm},>140 \mathrm{~mm}$ ) on different sampling dates in El Bilaim Lagoon (EB) and near A-Tor (AT). RF = relative frequency, INF = relative intensity of infestation. $1=<5,2=5-10,3=11-20,4=21-40,5=41-80,6=81-160,7=161-320$ worms per fish. $M=$ Mass mortality, $(M)=$ Sporadic mortality

significantly fewer worms than observed in winter 1975 in El Bilaim. A positive significant correlation existed between fork length and intensity of infestation

To compare length-weight relationships between A-Tor $L$. carinata samples and those from El Bilaim, data were transformed with common logarithms, separated into groups for small and large fish because large fish had a higher mean intensity of infestation, and fitted to the regression equation. Comparisons (Table 2) using an analysis of co-variance between both the large and small groups from both areas showed the same results. The means differed; one regression line did not represent both localities; the slopes were linear, and the intercepts differed, but the actual distance was slight. Some liberty was taken with the data from the large fish because the variances, although relatively close, were not homogeneous at the $5 \%$ level of significance. When comparing these same data for large fish from El Bilaim, separated into those fish with low against high pathological severity (relative units of $0-2$ vs $3-8$ ), the variances were homogeneous, but one regression line would represent all the data. 
Table 1. Mean values for condition coefficients (K) of Liza carinata in relation to fork length (FL) and intensity of infestation (IN) by Benedenia monticelli in the Gulf of Suez

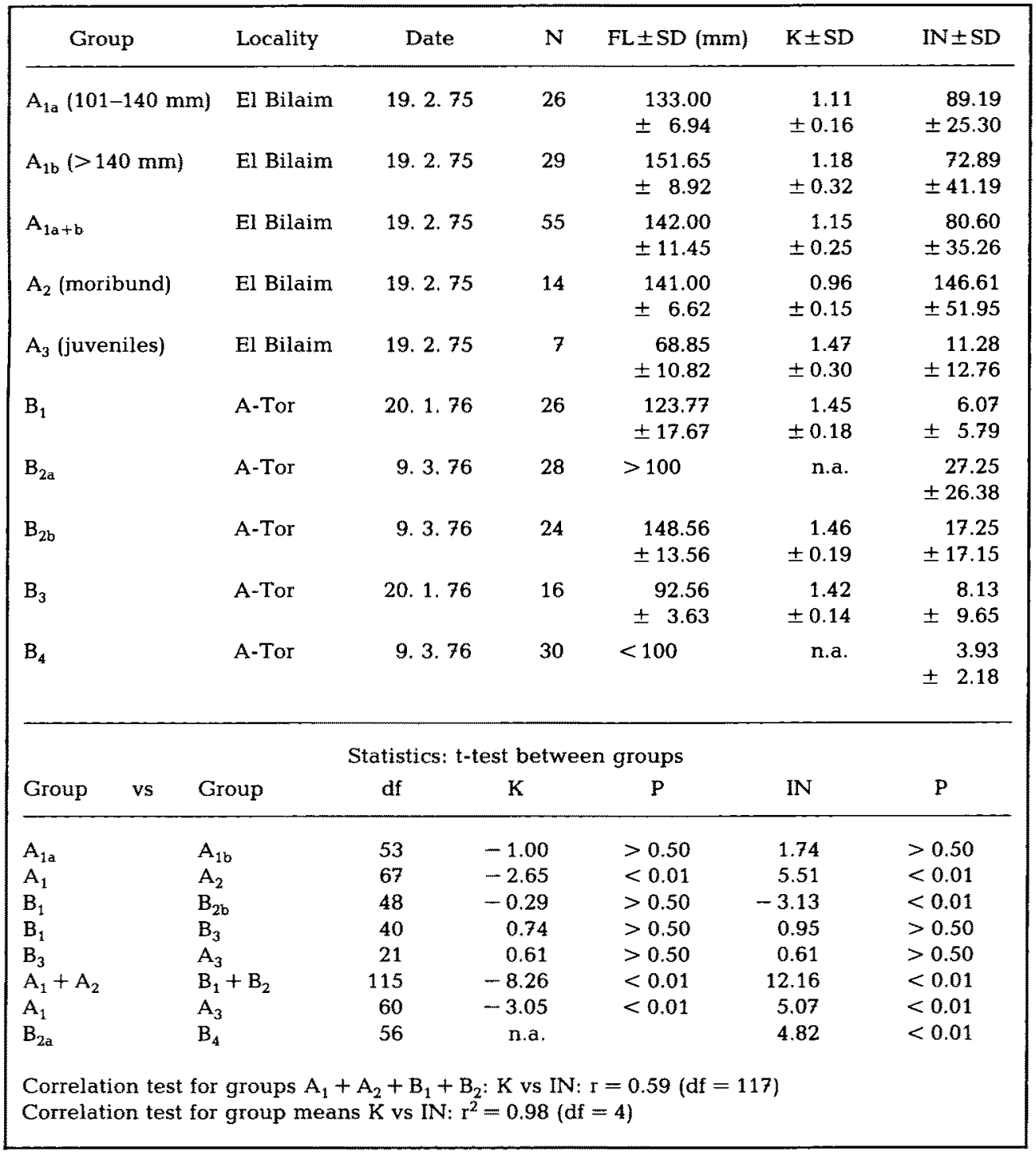

The severity of pathologically altered fish observed in El Bilaim did not occur in collections from A-Tor. Even when infested by 80 to 160 worms, specimens of $L$. carinata from A-Tor did not exhibit pathological signs. The condition coefficient $(\mathrm{K})$ of all the winter 1976 sample was relatively high, similar to that for juveniles in El Bilaim with few worms (Table 1). In some of the moderately and heavy infested fish (with worm load of 45-127) $\mathrm{K}$ was significantly lower than in the rest of the fish.

All mullets, including L. carinata, examined in summer months of 1975 (El Bilaim) 
Table 2. Logarithmically transformed fork length (L) - weight (W) relationships for Liza carinata from El Bilaim and A-Tor in the Gulf of Suez during periods of epizootics of Benedenia monticelli

\begin{tabular}{|lcccc|}
\hline Locality & $\begin{array}{c}\text { Length group } \\
(\mathrm{mm})\end{array}$ & Regression equation & $\begin{array}{c}\text { Correlation } \\
\text { coefficient }\end{array}$ & $\begin{array}{c}\text { Sample } \\
\text { size }\end{array}$ \\
\hline El Bilaim & $\leq 100$ & $\mathrm{~W}=-3.9162+3.0615 \mathrm{~L}$ & 0.98 & 30 \\
A-Tor & $\leq 100$ & $\mathrm{~W}=-4.0684+3.1019 \mathrm{~L}$ & 0.99 & 11 \\
El Bilaim & $>100$ & $\mathrm{~W}=-3.4258+2.7493 \mathrm{~L}$ & 0.82 & 67 \\
A-Tor & $>100$ & $\mathrm{~W}=-3.2973+2.7478 \mathrm{~L}$ & 0.95 & 50 \\
\hline
\end{tabular}

and 1976 (A-Tor) revealed sporadic infestations with few worms. Samples taken in January and March tended to be more infested in March, but juveniles of $L$. carinata always had a significantly lower intensity than fish $>100 \mathrm{~mm}$.

\section{INFESTATION IN CULTURED MULLETS}

Uninfested mullets maintained in seawater holding tanks developed infestations of Benedenia monticelli after adding infested mullets from the northern shores of the Gulf of Aqaba. These wild mullets, Liza subviridis, Valimugil seheli, and Mugil cephalus, had natural sporadic infestations of few worms during the winter months and even more sporadic ones during the spring. We followed the course of infestation in cultured mullets during the winter and spring seasons of 1974 through 1978 (Table 3).

Epizootics of $B$. monticelli developed in the holding tanks, usually within 3 to 4 weeks after an initial exposure to wild fish infested with fewer than 20 worms per fish. Mortalities started occurring within 4 to 6 weeks, with their magnitude and duration varying with the mullet species and with the intensity of infestation. For all species and intensities, some infested fish always survived and gradually lost their total infestations. The majority of stocked $L$. ramada died within a month during a 7 to 12 day period. Those few that survived gradually recovered within 4 to 6 weeks. Specimens of $L$. subviridus died sporadically over 6 weeks. Brief 2 to 3 day episodes of morbidity and mortality characterized epizootics on $L$. subviridis, $M$. cephalus, and $L$. carinata, and they affected only some of the individuals. Surviving fish gradually lost their infestations, with a few worms persisting in some fish for as long as 4 months, before finally being eliminated.

Cultured individuals of $V$. seheli and Crenimugil crenilabis did not acquire high intensities of worms, even though they host $B$. monticelli in nature. Even when maintained among heavily infested mullets of other species, those two species had infestations of fewer than 10 worms per fish except in one case with 35 worms.

\section{SITES OF INFESTATION AND PATHOLOGY}

Specimens of Benedenia monticelli attached to the integumental lining of the mouth, to the skin of the intermandibular fold, to the folds covered by adipose eyelids, and to the dorsal fin and integument surrounding its base. As mean intensity of infestation increased, worms ultimately extended their range to cover the entire body 


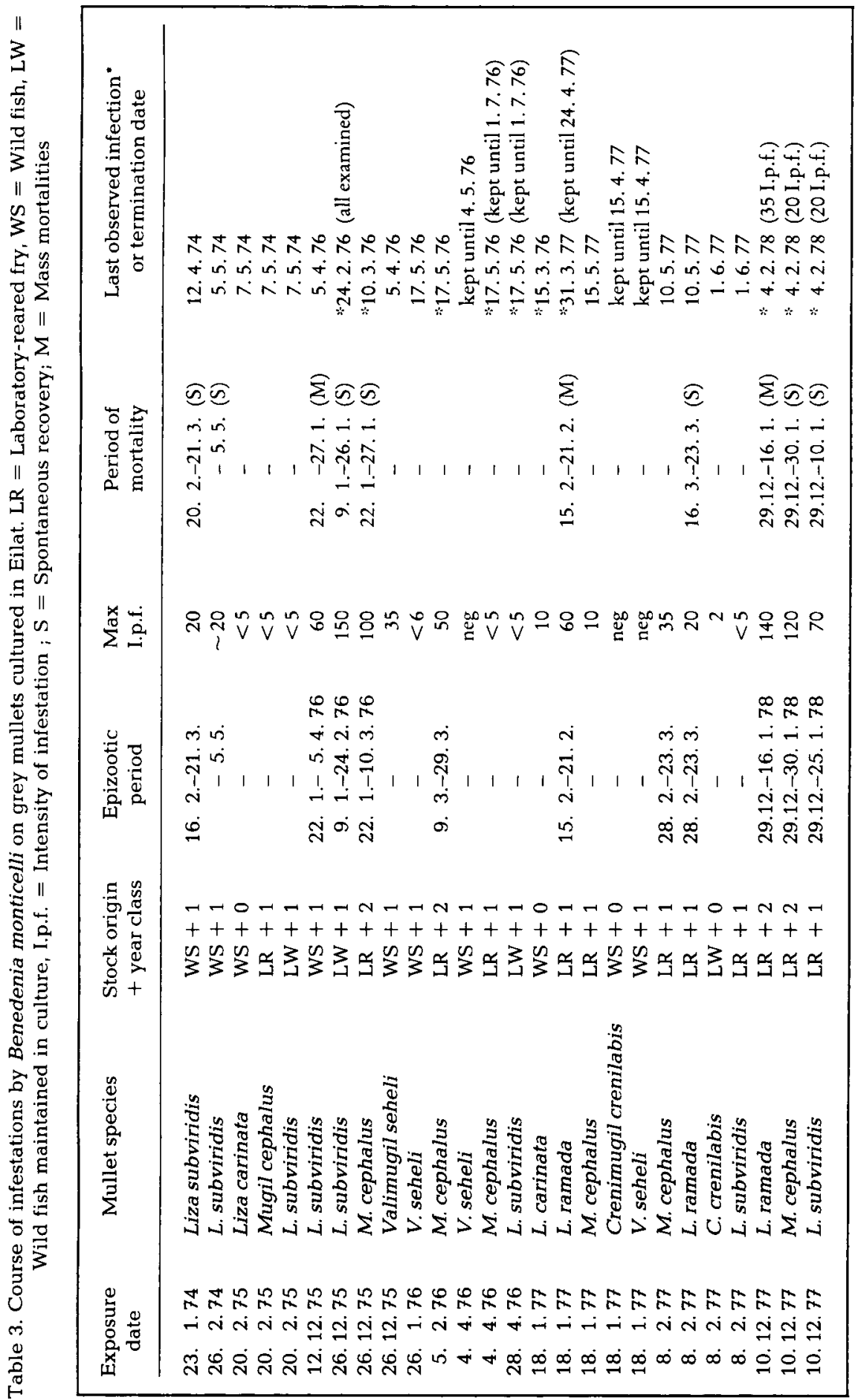




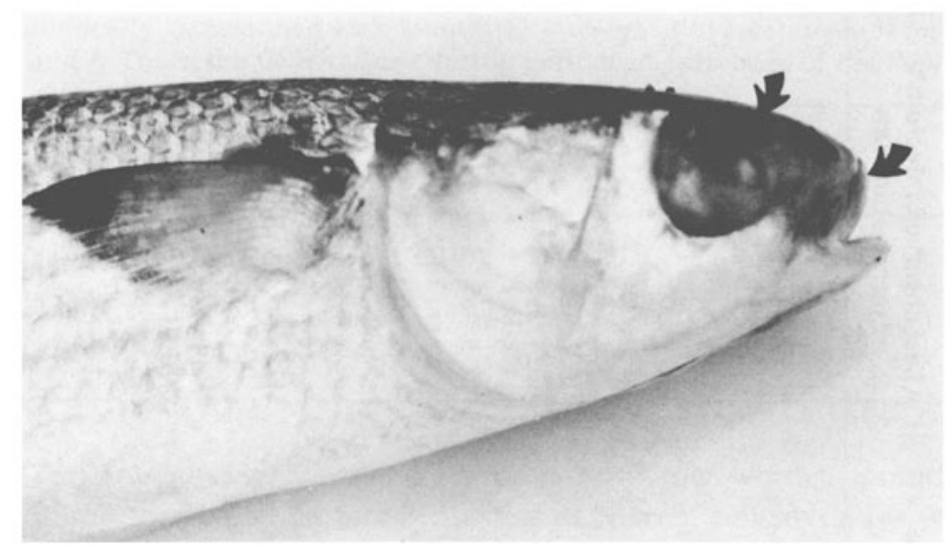

Fig. 9. Ocular damage and hemorrhaging in the upper lip and the nasal zone in Liza carinata heavily infested with Benedenia monticelli

surface. Sites of observed pathological changes typically corresponded with the common attachment sites. In both moribund and active fish, epithelium of snout and lips eroded, often exposing underlying bone. The mouth's integument was often severely impaired with hemorrhagic ulcerative lesions. In many fish the cornea and the adipose eyelid thickened and became chalky white, with epithelial layers gradually sloughing (Fig. 9). The intermandibular (gular) membrane became either perforated or completely degenerated in moribund fish, and the opercular membrane was often completely eroded (Fig. 6). The epithelium on and at the base of the dorsal fin (Fig. 10) and in margins of lesions in the pharynx and elsewhere on the skin became hyperplastic and necrotic, occasionally with hemorrhaging and gradual sloughing. In extensive infestations, similar lesions developed around the ventral fins. In general, a gradual degradation of epithelium exposed the underlying dermal or collagenous layers. When collagenous, the layer was distorted. A severe inflammatory reaction, often involving the entire adjacent dermal and sub-dermal layers, was evident as congestion, edema, and infiltration of eosinophils, macrophages, and lymphoctyes. Bacteria often occurred abundantly in necrotic residues of the epithelial layer and in the exposed distorted dermal layer.

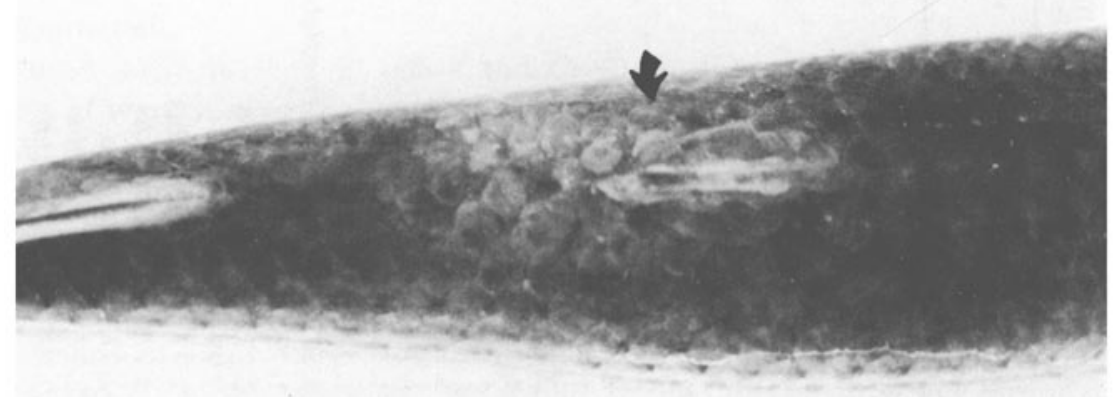

Fig. 10. Hyperplasia of the skin epithelium near the dorsal fin in Mugil cephalus infested by Benedenia monticelli 

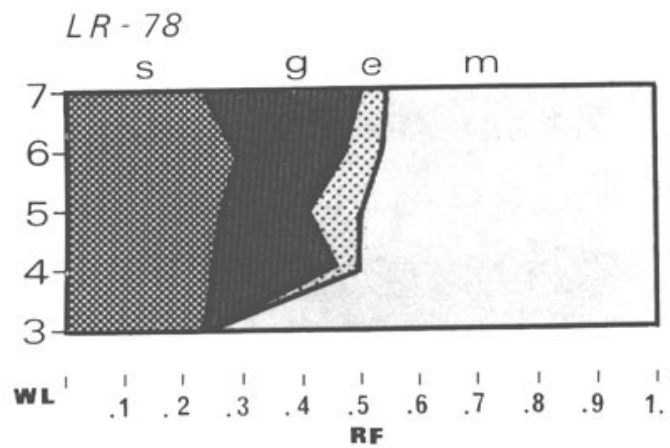

\section{LR - 77}

1.
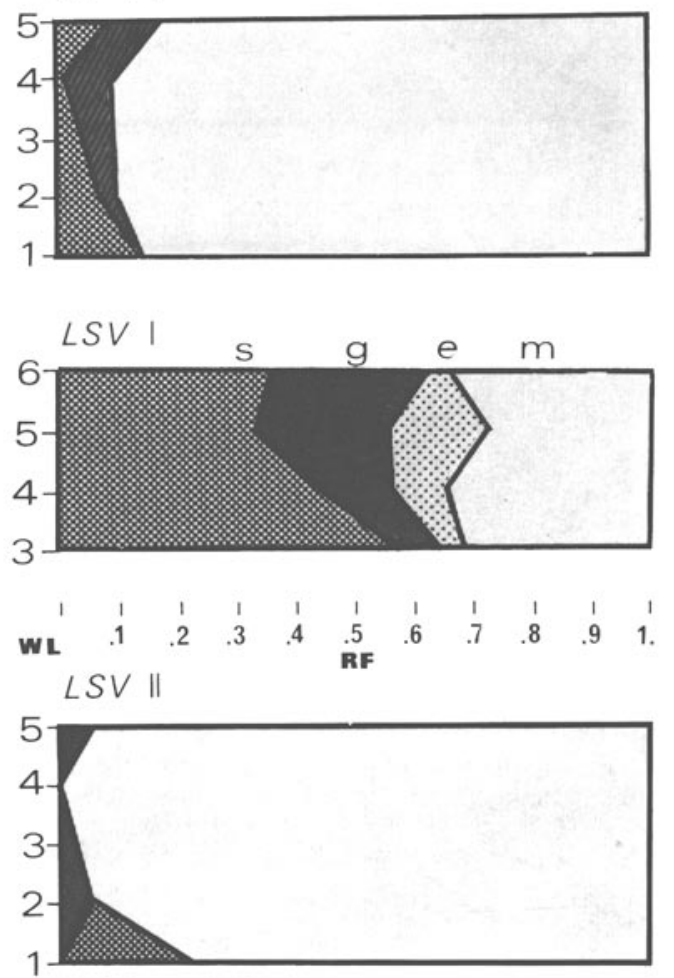

Fig. 11. Sites of Benedenia monticelli on grey mullets. Relative frequency of occurrence (RF) on different organs: skin (s); intermandibular folds ( $g$ ), eyes (e), mouth in relation to the relative intensity of worms per fish. $\mathrm{WL}=$ worm load: $1=<5,2=5-10,3=11-20,4=21-40,5=41-80$, $6=81-160,7=161-320$, LR $78=$ Liza ramada, culture, 1978 (morbid infestation, $n=33$ ). LR $77=$ L. ramada, culture, 1977 (morbid infestation, $\mathrm{n}=16$ ). LSV I = L. subviridus, culture, 1975 (morbid infestation, $\mathrm{n}=10$ ). LSV II $=$ L. subviridus, wild and culture, 1977 and $1978(\mathrm{n}=11)$ 


\section{$\angle C / C$}
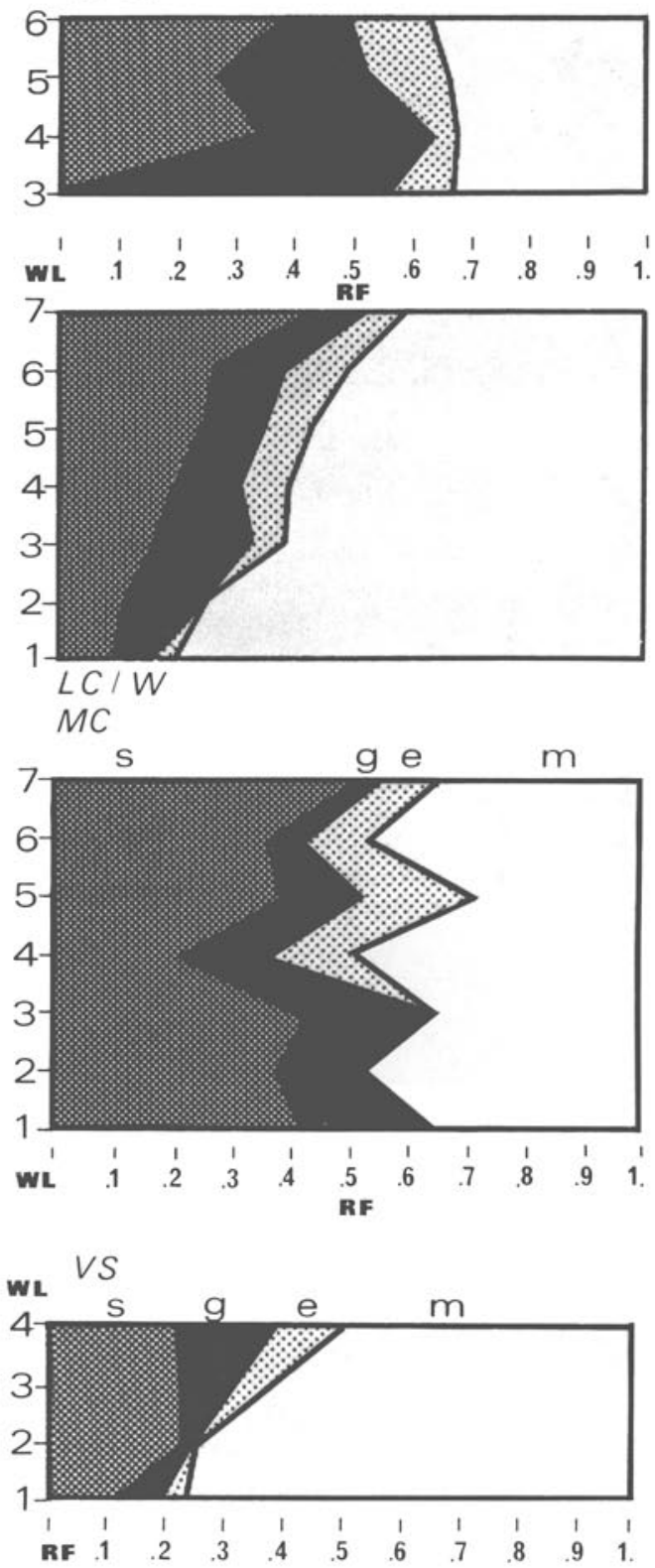

Fig. 12. Sites of Benedenia monticelli on grey mullets: LC/C $=$ Liza carinata, culture $(\mathrm{n}=12)$. $\mathrm{LC} / \mathrm{W}=L$. carinata, wild population from the Gulf of Suez $(\mathrm{n}=137) . \mathrm{MC}=$ Mugil cephalus, culture $(\mathrm{n}=30)$. VS $=$ Vagimugil seheli, culture and wild population $(\mathrm{n}=102)$. For explanation see Figure 11 
Susceptibility of infestation and vulnerability to subsequent pathogenic effects varied considerably according to mullet species and even to stock of a mullet species. An important aspect in considering pathological alterations induced by $B$. monticelli is the pattern of common sites for worms over the host body (Figs 11, 12). Interspecific differences in common sites of infestations could be detected most easily when few worms occurred on a host. In culture conditions and as intensity of infestations increased, these differences tended to be less pronounced. When few worms infested any species in its natural habitat, the pharyngeal integument was the most common site for infestation.

Of the infested mullets, the Mediterranean Sea species Liza ramada (Syn. Mugil capito) and $L$, subviridis appeared to be extremely susceptible to disease, succumbing from as few as 6 to 10 worms on $L$. subviridis and from 10 to 50 worms on $L$. ramada. In these fishes, most worms occurred in the oral region inducing severe pharyngeal lesions and hemorrhaging (Fig. 11). When $L$. ramada and $L$. subviridis became heavily infested in culture conditions, worms spread evenly on the skin and pharynx. Liza carinata, $L$. aurata, and Mugil cephalus did not succumb until infestations reached 50 and in some instances 100 worms per fish.

Infestations of $B$. monticelli on both $L$. carinata and $M$. cephalus were seldom restricted to specific sites, even when few worms were present (Fig. 12). Occasionally, worms on wild $M$. cephalus concentrated on the lower jaw's intermandibular folds. In culture conditions, infestations on $M$. cephalus occurred more commonly on the skin than for other infested mullets (Fig. 12). When $L$. carinata became infested in culture, worms were distributed over the fish's body, and the induced pathological alterations appeared similar to those observed in natural infestations (Fig. 12).

Once epizootics with their high density of worms declined, the distribution of worms also changed. Worms appeared to avoid necrotic areas in the pharynx and attach to more interior, undamaged zones toward the branchial zone and eventually disappear entirely from the mouth and branchial cavity. In the final stage of infestation, the few remaining worms occurred on the skin only, mainly around the dorsal fin.

\section{DISCUSSION}

Clinical data on microcotylid infestations in the yellowtail (Eto et al., 1976) and the present authors' data on infestations on Siganus luridus suggest that anaemia characterizes microcotylid gill infestations in fishes. As another example, we observed a severe case of anaemia in juveniles of Acanthopagrus bifasciatus (Sparidae) from the Gulf of Aqaba that had a high intensity of a microcotylid. The hematophagous nature of the microcotylids was evident from hematin cells lining their intestine (e.g. Halton, 1976) plus the presence of red blood cells and hematin in their intestinal lumen. Even though we demonstrated a high correlation between the intensity of Allobivagina sp. on the gills and hematocrit values in S. luridus, we do not think that all the blood loss (erythrocytes) from the hosts can be attributed to feeding by the worms or to excessive hemorrhaging which was never observed.

In the yellowtail, the decline in hematocrit values was not as extreme as in infested specimens of S. luridus, and the report of Eto et al. (1976) does not relate specific intensity of infestation to hematocrit values. Clinical and biochemical data on infested yellowtail presented by those authors suggested that the fish were malnourished, which 
led the authors to suggest that iron deficiency was a causative co-factor in the anaemia. Eto et al. (1976) supported their hypothesis by pointing out a similar anaemia (microcytotic hypochromemia) occurs in iron-deficient fishes and domestic animals. Anaemia also occurs in humans infected by ancylostome hookworms, and it can be reversed by administering iron (e.g. Faust et al., 1970; Hall, 1981).

Disease and integumental lesions induced by the capsalids Neobenedenia melleni (as Epibdella m.) in various marine aquarium fishes (Jahn \& Kuhn, 1932; Nigrelli \& Breder, 1934), Benedenia seriolae in yellowtail (Hoshina, 1968), Entobdella solea in Dover sole, and B. monticelli in mullets appear similar. Benedenia monticelli fed on integumental epithelium, and this layer along with adjacent epithelium eroded. The observed ulcerative inflammation and necrosis of the exposed dermal layer appeared to result from secondary bacterial invasion. Septicemia developing from this bacterial infestion could be involved in deaths of fish (Liza subviridis and Liza ramada) infested by a relatively small number of individuals concentrating on the oral integument. Even though the worm feeds on host tissue, it seems to abandon the ulcerative necrotic integument. Probably it leaves that site for lack of host epidermis and associated mucus, the presumed normal food source (e.g. Halton \& Stranock, 1976). In that process of abandonment, some individuals attach on new sites and some do not. Consequently, extension in range of the lesions evidently results in a gradual decline of infestation. This gradual loss of worms was typical for $S$. luridus surviving the microcotylid infestation on its gills and for mullets surviving the capsalid infestation on their integument. Moreover, there were no repetitive epizootic sequences after the infestations on these fishes initiated a decline.

Spontaneous loss of parasites is a common phenomenon for parasitic infections on fishes, as exemplified by the capsalid Neobenedenia melleni (e.g. Jahn \& Kuhn, 1932; Nigrelli \& Breder, 1934). The biological process involved in this acquired tolerance to monogenean infestations remains poorly known, but may be influenced by the adult and its ability to survive and to attach as well as by the larva in regard to its biology, the host's chemical substances, and environmental conditions (Kearn, 1981).

Conditions of overcrowding and adverse ambient conditions promote epizootic diseases (Snieszko, 1974). The apparent relative rarity of parasitic-related mass mortalities in wild fish populations supports this contention, since fish usually are not confined, and they can often avoid harsh environmental conditions. Biological information on mullets and their parasites and on hydrography related to El Bilaim is fragmentary. Nevertheless, available data suggest that a $B$. monticelli epizootic affecting $L$. carinata is not exceptional, but rather a recurring event in winter months of some years and occasionally even other months. Our studies of the mullet infestations in the A-Tor region also suggest that certain winter conditions in the Gulf of Suez promote epizootics. In the Gulf of Suez, water temperature drops below $18^{\circ} \mathrm{C}$, and, in the coastal water of A-Tor Bay and in the semi-enclosed El Bilaim Lagoon, it can decrease to $13^{\circ} \mathrm{C}$. Low temperature inhibits some immune responses in fishes (Avtalion, 1981). In the Gulf of Aqaba where intensity of infestations of $B$. monticelli on mullets, even during winter months, never exceeded 20 parasites per fish, ambient water temperature remained at 22 to $25^{\circ} \mathrm{C}$ throughout the year. On the other hand, ambient water temperature in the culture tanks where mullets died from benedeniasis was also 22 to $25^{\circ} \mathrm{C}$.

Overcrowding probably serves as an important promoting factor. In crowded condi- 
tions, monogenean larvae have readily accessible hosts, and those hosts are stressed. Fish in holding tanks were crowded as were individuals of $L$. carinata in the small semienclosed lagoon during the winter months. Those latter individuals, all mature and $>$ $100 \mathrm{~mm}$ in length, had a low condition coefficient which could have resulted either from insufficient feeding, a spent reproductive state, or from heavy infestation. Mullets of all other species including juveniles had few parasites and were in good condition.

The signifant negative correlation demonstrated between the condition coefficient of individual fish and their intensity of infestation, as well as the severity of the pathological condition, strongly suggests infestation as the primary cause for weight loss. On the other hand, an adverse physiological state evident by the decline in fish condition could have been the primary factor in the vulnerability of the fish to infestation and its morbid consequences.

In A-Tor, fish of the $>100 \mathrm{~m}$ size class sampled in March, were in far better condition than El-Bilaim fish of the same size class sampled in February. Although low condition was evident in some moderately and heavily infested fish, the loss of weight was not evident in the moderately infested fish (with 50 to 80 worms).

Acknowledgements. Studies on grey mullets were supported by Grant No. 94 of the United States Israel Binational Science Foundation. The work was conducted in part in cooperation with the US Department of Commerce, NOAA, NMFS, under PL 88-309, Project 2-393-R.

\section{LITERATURE CITED}

Anderson, J. I. W. \& Conroy, D. A., 1968. Extensive infestation by Entobdella soleae in brood stock of Dover sole. - Bull. Off. int. Epizoot. 69, 1129-1137.

Avtalion, R. R., 1981. Environmental control of the immune response in fish. In: CRC critical reviews in environmental control. Ed. by C. P. Straub. CRC Press, Boca Raton, 11, 163-188.

Eto, A., Sakomoto, S., Fujii, M. \& Yone, Y., 1976. Studies on an anaemia of yellowtail parasitized by a trematode, Axine (Heteraxine) heterocerca. - Rep. Fish. Res. Lab., Kyushu Univ. 3, 45-51.

Faust, E. C., Russell, P. F. \& Jung, R. C., 1970. Clinical parasitology. Lea \& Febiger, Philadelphia, $890 \mathrm{pp}$.

Hall, A., 1981. Parasitic infections and human physical performance. - Parasitology 82, 42-43.

Halton, D. W., 1976. Diclidophora merlangi: sloughing and renewal of hematin cells. - Expl Parasit. $40,41-47$.

Halton, D. W. \& Stranock, S. D., 1976. The fine structure and histochemistry of the caecal epithelium of Calicotyle kroyeri (Monogenea: Monopisthocotylea). - Int. J. Parasit. 6, 253-263.

Hoshina, T., 1968. On the monogenetic trematode Benedenia seriolae, parasitic on yellowtail, Seriola quinqueradiata. - Bull. Off. int. Epizoot. 69, 1179-1191.

Jahn, T. L. \& Kuhn, L. R., 1932. The life history of Epibdella melleni MacCallum 1927, a monogenetic trematode parasitic on marine fishes. - Biol. Bull. mar. biol. Lab., Woods Hole 62 , 89-111.

Kearn, G. C., 1981. Behaviour of oncomiracidia, - Parasitology 82, 57-59.

Lawler, A. R, 1977. Monogenetic trematodes of pompano. In: Disease diagnosis and control in North American marine aquaculture. Ed. by C. J. Sindermann. Elsevier, Amsterdam, $265-267$.

Nigrelli, R. F., 1939. Mortality statistics for specimens in the New York Aquarium. Zoologica, N. Y. $25,525-552$.

Nigrelli, R. F., 1943. Causes of diseases and death of fishes in captivity. - Zoologica, N. Y. 28, $203-216$.

Nigrelli, R. F. \& Breder, C. M., 1934. The susceptibility and immunity of certain marine fishes to Epibdella melleni, a monogenetic trematode. - J. Parasit. 20, 259-269. 
Paperna, 1. 1975. Parasites and diseases of the grey mullet (Mugilidae) with special reference to the seas of the Near East. - Aquaculture 5, 65-80.

Paperna, I. \& Overstreet, R. M., 1981. Parasites and diseases of mullets (Mugilidae). In: Aquaculture of grey mullets. Ed, by O. H. Oren. Cambridge Univ. Press, Cambridge, 411-493.

Snieszko, S. F., 1974. The effect of environmental stress on outbreak of infectious diseases of fishes. - J. Fish Biol. 6, 197-208. 